\title{
Rearing the predaceous mite, Amblyseius swirskii (Athias-Henriot) (Phytoseiidae) on artificial diets
}

\author{
M. Eleawa and Dalia A. Waked \\ Plant Protec. Res. Inst., Agric. Res. Cent., Dokki, Giza, Egypt.
}

\begin{abstract}
This study was to develop a suitable artificial diet for mass rearing the economically important phytoseiid predator, Amblyseius swirskii which considered one of the most effective phytoseiid species used in agricultural systems for the control of spider mites. The basic artificial diet (AD) was composed of honey, glucose, milk, yeast and fresh egg yolk. This diet was enriched as (AD1) by adding hemolymph from mulberry silkworm, Bombyx mori. Predators fed on Tetranychus urticae and AD1 had shorter immature and pre-oviposition periods than those fed on the other diets. The total number of deposited eggs was significantly higher for females fed on AD1 than those maintained on the other diets. There weren't significant differences between T. urticae and bee bread in the total number of deposited eggs and longevity. This indicates that rearing A. swirskii on bee bread was successful. Therefore this artificial diet can serve as a potentially useful food source for the long-term maintenance of $A$. swirskii populations.
\end{abstract}

Key words: Amblyseius swirskii; Artificial diets; Mass rearing.

\section{INTRODUCTION}

Mites of the genus Amblyseius are characterized as specialized pollen feeders and generalist predators (Abou-Setta and Childers, 1989 and Oliver et al., 1996). Phytoseiid mite species, however clearly differ in their ability to utilize pollen (McMurtry and Croft, 1997) and characterized the life styles on the basis of feeding habits in four major types. Among other aspects, each group differs in the extent to which they utilize pollen as a food source: type I (spider mite specialists) don't feed on pollen at all; type II (less specialized spider mite feeders); type III (generalists) feed on pollen but prefer or have better performance on prey and type IV (pollen feeders) show the highest performance on a pollen diet. Population dynamics of Euseius species, which are mostly found in arboreal habitats, are often related to pollens found on the foliage rather than to the presence of any prey species (Grout and Richards, 1992). Amblyseius swirskii can feed on various types of food including arthropod prey but also plant materials like pollens and honeydew (Momen and El-Saway, 1993). Previous studies showed that $A$. swirskii can successfully develop and reproduce on a wide range of food sources such as, eriophyid mites (El-Laithy 1998 and Park et al., 2010), spider mites (Xu and Enkegaard, 2010) and plant pollens (Kutuk and Yigit, 2011and Park et al., 2011). The availability of an effective artificial diet for phytoseiids could eliminate many of the problems associated with their mass rearing (Kennett and Hamai 1980). Whereas a good body of literature exists on artificial diets for insect predators (Thompson, 1999 and Riddick, 2009), relatively few studies have focused on the development of artificial diets for phytoseiid mites. McMurtry and Scriven, 1966 tested several diets for four phytoseiid species: Amblyseius limonicus Garman and McGregor, Amblyseius hibisci (Chant), Typhlodromus occidentalis Nesbitt, and Typhlodromus rickeri Chant. Their results showed that immatures development was poor and oviposition rates were low compared to natural prey or pollen. Shehata and Weismann, 1972 reared Phytoseiulus persimilis (Athias-Henriot) on three artificial diets and larva developed to females that deposited eggs. However, the female offspring failed to produce eggs, and had a smaller size and shorter longevity than conspecifics preying on T. urticae. Kennett and Hamai, 1980 found that seven out of nine species of phytoseiid mites could develop and reproduce when fed an artificial diet composed of honey, sugar, yeast flakes, yeast hydrolysate, enzymatic casein hydrolysate, and fresh egg yolk. However, the oviposition rate of all species fed on artificial diet was only about one third of that achieved on natural diets. Abou-Awad et al., 1992 showed that Amblyseius gossipi El-badry and A. swirskii developed, survived and reproduced on several artificial diets consisting of yeast, milk, cystine, proline, arginine, sucrose, glucose, streptomycin sulphate, and sorbic acid. However, females fed on the best performing artificial diet had lower oviposition rates than those on natural diet. Ogawa and Osakabe, 2008 reported that an artificial diet composed of yeast components, saccharides, and egg yolk supported development and survival of Neoseiulus californicus (McGregor), but again fecundity on the artificial diet was low. The above studies suggest that, although phytoseiid mites can develop on different artificial diets, fecundity in most cases was negatively affected. Hence, for making a diet suitable for commercial mass rearing of phytoseiids, the factor to be improved is reproduction. Several studies have demonstrated that the use of insect materials in artificial media can enhance survival and oviposition of entomophagous insects (Grenier and De Clercq 2003). For instance, many artificial media for egg parasitoids of the genus 
Trichogramma contain lepidopteran pupal hemolymph and/or pupal holotissues to stimulate egg lying by the parasitoid females or to provide adequate nutrition for development of the larvae (Liu et al., 1979; Strand and Vinson, 1985; Nettles, 1990 and Lu" et al., 2012). Also, the fecundity of the predatory anthocorid Orius insidiosus (Say) was significantly increased when the bugs were fed on an artificial diet supplemented with a cell line derived from eggs of the Indian meal moth Plodia interpunctella $\mathrm{Hu}$ bner (Ferkovich and Shapiro, 2004). Conceivably, insect materials like hemolymph could also be useful to supply nutritional factors for growth and reproduction of predatory mites such as $A$. swirskii. In the present study, we determined the life table parameters of $A$. swirskii when fed on Bee bread, spider mite (Tetrantchus urticae), or a meridic artificial diet modified from (Ogawa and Osakabe, 2008) and a similar diet supplemented with insect hemolymph.

\section{MATERIALS AND METHODS}

\section{Mites' cultures:}

Laboratory cultures of the mites were established from field collections of the spider mite Tetranychus urticae Koch and A. swirskii on Phaseolus vulgaris L. in Abou-kaber, Sharkia governorate. Mite cultures were maintained in separate climatic rooms at $27 \pm 2$ ${ }^{\circ} \mathrm{C}$ and $60-70 \%$ R.H. Spider mites were reared on bean plants; while $A$. swirskii was reared on detached bean leaves prepared as follows. Several young fully expanded bean leaves were placed underside up on a wet cotton wool layer in a plastic tray $(30 \times 20 \mathrm{~cm})$. The wet cotton wool prevented mite escape and maintain leaf freshness for two weeks. The cotton wool was maintained wet by adding water when necessary. Bean leaves were infested with mixed stages of T. urticae and 24h later A. swirskii females were added.

\section{Bee bread:}

Bee bread was kept in a refrigerator at $5{ }^{\circ} \mathrm{C}$ for need.

\section{Preparation of artificial diets:}

The artificial diets were composed of (AD): honey $(10 \mathrm{~g})$, glucose $(10 \mathrm{~g})$, milk $(20 \mathrm{ml})$, yeast $(5 \mathrm{~g})$ and fresh egg yolk $(10 \mathrm{ml})$. During preparation the components were dissolved in appropriate amounts of distilled water. The second diet (AD1): consisted of $75 \%$ AD supplemented with $25 \%(\mathrm{w} / \mathrm{w})$ hemolymph of mulberry silkworm larvae (Bombyx mori) originating from a culture at Plant Protection Research Institute. The larval hemolymph was collected from live $B$. mori larvae which were immersed in a water bath at $60^{\circ} \mathrm{C}$ for $10 \mathrm{~min}$. to avoid melanization of the hemolymph. The hemolymph was then lyophilized and stored in a deep freeze at $-18^{\circ} \mathrm{C}$.
The lyophilized hemolymph was redissolved using distilled water before being added to the diet.

\section{Experimental set-up:}

The arenas used in this study were $3 \times 3 \mathrm{~cm}$ of mullbarry leaf discs placed lower surface up on a water saturated sponge pads. Strip of moistened absorbent cotton was placed around the outside edge of the leaves. Thirty newly hatched predator larvae were used for the treatments, $\mathrm{AD}, \mathrm{AD} 1, T$. urticae immatures and bee bread that placed individual on arenas supplied with the food diets to be evaluated. Arenas were examined daily and predator developmental stages were recorded. Each female was paired with a male that was reared on the same diet as the female. Freshly diet was made available to the predator by providing each arena with a small amount of test diet and was replaced at 48-72 $\mathrm{h}$. The diet must be stored well and preferably have a low water content to minimize molding when used as a food source for mite rearing. Observations were made every $24 \mathrm{~h}$ until all individuals had reached adulthood. After completing immature development, each female was paired with a male and observed daily to determine the preoviposition and oviposition periods, longevity and fecundity. Progeny from females of the same age were transferred to new ones and fed on the same diet as their parents in order to determine the sex ratio of the offspring for each treatment. The experiments were undertaken in a growth chamber at $27 \pm 2{ }^{\circ} \mathrm{C}, 65 \pm 5 \%$ R.H.

\section{Statistical analysis:}

Data were subjected to statistical analysis using one way analysis of variance, ANOVA (Duncan's, 1955).

\section{RESULTS AND DISCUSSION}

The developmental times of male and female immature stages, larvae and protonymphs didn't differ among diets Table (1). A. swirskii of larvae can develop into protonymphs without food but the protonymphs need food for further development. However, the developmental time of female and male deutonymphs were significantly affected by diet. Female deutonymphs reared on AD1, bee bread and T. urticae took significantly less time to develop to adulthood than those fed on the other diet, AD. The total developmental time of females fed on AD1 was 4.43 days being significantly shorter than females fed on T. urticae and bee bread. The developmental time was the longest 6.06 days for the females fed 
Table (1): Developmental time (days) of A. swirskii immature stages fed on different diets

\begin{tabular}{|c|c|c|c|c|c|}
\hline \multirow{2}{*}{ Diet } & \multirow{2}{*}{ Sex } & \multicolumn{4}{|c|}{ Developmental stages } \\
\hline & & Larva & Protonymph & Deutonymph & Total immatures \\
\hline \multirow{2}{*}{ T. urticae } & $q$ & $0.83^{\mathrm{a}}$ & $2.16^{\mathrm{a}}$ & $2.08^{\mathrm{ab}}$ & $5.07^{b}$ \\
\hline & o & $0.77^{\mathrm{a}}$ & $1.88^{\mathrm{a}}$ & $1.94^{\mathrm{a}}$ & $4.59^{\mathrm{a}}$ \\
\hline \multirow{2}{*}{$\mathrm{AD}$} & q & $1.14^{\mathrm{a}}$ & $2.28^{\mathrm{a}}$ & $2.64^{\mathrm{a}}$ & $6.06^{\mathrm{a}}$ \\
\hline & Oे & $1.11^{\mathrm{a}}$ & $1.83^{\mathrm{a}}$ & $2.00^{\mathrm{a}}$ & $4.94^{\mathrm{a}}$ \\
\hline \multirow{2}{*}{ AD1 } & q & $0.80^{\mathrm{a}}$ & $1.90^{\mathrm{a}}$ & $1.73^{\mathrm{c}}$ & $4.43^{\mathrm{bc}}$ \\
\hline & $\hat{0}$ & $0.70^{\mathrm{a}}$ & $1.80^{\mathrm{a}}$ & $1.40^{\mathrm{b}}$ & $3.90^{\mathrm{b}}$ \\
\hline \multirow{2}{*}{ Bee bread } & q & $0.86^{\mathrm{a}}$ & $1.81^{\mathrm{a}}$ & $2.18^{\mathrm{ab}}$ & $4.85^{\mathrm{b}}$ \\
\hline & 齐 & $0.87^{\mathrm{a}}$ & $1.75^{\mathrm{a}}$ & $1.87^{\mathrm{a}}$ & $4.49^{\mathrm{a}}$ \\
\hline
\end{tabular}

Table (2): Longevity and reproduction of A. swirskii fed on different diets

\begin{tabular}{lcccc}
\hline \multirow{2}{*}{\multicolumn{1}{c}{ Parameter }} & \multicolumn{2}{c}{ Diets } & AD1 & Bee bread \\
\cline { 2 - 5 } & T. urticae & AD & $1.52 \pm 0.12$ & $1.77 \pm 0.12$ \\
\hline Pre-oviposition period (days) & $1.58 \pm 0.07$ & $2.18 \pm 0.84$ & $15.73 \pm 0.29$ & $17.29 \pm 0.18$ \\
\hline oviposition period (days) & $18.25 \pm 0.37$ & $11.22 \pm 0.22$ & $1.61 \pm 0.10$ \\
\hline Post-oviposition period (days) & $2.60 \pm 0.11$ & $1.86 \pm 0.14$ & $2.10 \pm 0.07$ & $19.35^{\mathrm{a}}$ \\
\hline Female longevity (days) & $22.43^{\mathrm{a}}$ & $15.26^{\mathrm{b}}$ & $20.67^{\mathrm{a}}$ \\
\hline Fecundity (total deposited eggs) & $41.05 \pm 0.68^{\mathrm{b}}$ & $30.81 \pm 0.55^{\mathrm{c}}$ & $49.05 \pm 0.42^{\mathrm{a}}$ & $37.64 \pm 0.51^{\mathrm{b}}$ \\
\hline Oviposition (eggs/female/day) & 2.24 & 2.74 & 3.11 & 2.17 \\
\hline
\end{tabular}

Means in columns followed by the same letter are not significantly different at the 5\% level according to Duncan's multiple range tests.

Table (3): Hatchability, survival and adult emergence of A. swirskii on different diets

\begin{tabular}{lccc}
\hline \multicolumn{1}{c}{ Diets } & $\begin{array}{c}\text { Hatchability } \\
\%\end{array}$ & $\begin{array}{c}\text { Immatures } \\
\text { survival } \%\end{array}$ & $\begin{array}{c}\text { Development } \\
\%\end{array}$ \\
\hline T. urticae & $94.28^{\mathrm{a}}$ & $97.41^{\mathrm{a}}$ & $92.42^{\mathrm{a}}$ \\
\hline $\mathrm{AD}$ & $90.00^{\mathrm{a}}$ & $90.69^{\mathrm{b}}$ & $74.60^{\mathrm{c}}$ \\
\hline AD1 & $92.85^{\mathrm{a}}$ & $96.82^{\mathrm{a}}$ & $90.76^{\mathrm{a}}$ \\
\hline Bee bread & $91.42^{\mathrm{a}}$ & $93.92^{\mathrm{b}}$ & $82.81^{\mathrm{b}}$ \\
\hline $\begin{array}{l}\text { Means in columns followed by the same letter are not } \\
\text { significantly different at the 5\% level according to Duncan's } \\
\text { multiple range tests. }\end{array}$
\end{tabular}

on AD. Nearly all individuals reached adulthood on the different diets. The artificial diets tested were modified from that formulated by Ogawa and Osakabe, 2008 that compared with bee bread and the spider mite T. urticae (Xu and Enkegaraad, 2010). Our findings indicated that $A$. swirskii could develop with similar or even better success on an artificial diet AD1 as compared to T. urticae.

Oviposition period and female longevity were longer on T. urticae, than on bee bread, AD1 and AD Table (2). The total number of eggs was significantly higher for females offered AD1 with mean 49.05 eggs versus the other diets that were $41.05,37.64$ and 30.81 eggs for $T$. urticae, bee bread and $\mathrm{AD}$, respectively. There wasn't significant difference between $T$. urticae and bee bread in fecundity and longevity. The daily oviposition rate of $A$. swirskii reared on AD1 was significantly higher (3.11 eggs) than that of females reared on the other diets.

Table (3) indicated that hatchability percentage didn't differ significantly on the different diets. The highest intrinsic rates of increase was observed when
A. swirskii fed on T. urticae and this value was similar to that reported for A. swirskii when fed on the two spotted spider mite (El-Laithy and Fouly, 1992). Adults' development of A. swiriskii was significantly affected by the different diets tested and there wasn't significant difference between feeding A. swirskii on T. urticae and AD1. This indicated the importance of the nutritional quality of a diet on the development of A. swirskii. The artificial diet developed by (Ogawa and Osakabe, 2008) supported immatures development and survival of the predatory mite, $N$. californicus but its oviposition rate on this diet was negligible compared with a diet of $T$. urticae. However, a slightly modified version of this artificial diet used in our study (AD, without hemolymph) proved suitable to support development of $A$. swirskii and also, allowed some reproduction. The oviposition rate of A. swirskii on AD1 was higher than that on an artificial diet designed by Abou-Awad et al., 1992.

The relatively good performance of $A$. swirskii on artificial diet AD1 might be due to the generalist feeding habits of this phytoseiid mite (Momen and ElSaway, 1993). Nettles, 1990 and Grenier and Declercq, 2003) noted that adding insect components such as hemolymph to artificial media enhanced their acceptability and improved their nutritional quality for a number of entomophagous insects. Hemolymph of lepidopteran larvae or pupae was used in artificial media for parasitoid especially for Trichogramma species (Strand and Vinson, 1985). Our study indicates, that supplementing artificial diets with insect hemolymph may also be useful to improve their nutritional value for predatory arthropods. Further research is needed to identify the components of the insect hemolymph which are responsible for 
the increased performance. The artificial diet AD1 supported development and reproduction of $A$. swirskii to the same extent as a factitious prey which was routinely used in the mass rearing of the phytoseiid, indicating the potential of artificial diets to rationalize the mass production of this economically important biological control agent.

\section{REFERENCES}

Abou-Awad, B. A.; Reda, A. S. and Elsawi, S. A. 1992. Effects of artificial and natural diets on the development and reproduction of two phytoseiid mites Amblyseius gossipi and Amblyseius swirskii (Acari: Phytoseiidae). Insect Sci. Appl., 13:441-445.

Abou-Setta, M. M. and Childers, C. C. 1989. Biology of Euseius mesembrinus (Acari: Phytoseiidae): life tables and feeding behavior on tetranychid mites on citrus. Environ. Entomol., 18: 665-669.

Duncan, D. B. 1955. Multiple ranges and multiple F. test. Biometrics, 11: 1-41.

El-Laithy, A. Y. 1998. Laboratory studies on growth parameters of three predatory mites associated with eriophyid mites in olive nurseries. J. Plant Dis. Prot., 105:78-83.

El-Laithy, A. Y. M. and Fouly, A. H. 1992. Life table parameters of the two phytoseiid predators Amblyseius scutalis (Athias- Henriot) and A. swirskii A.-H. (Acari: Phytoseiidae) in Egypt. J. Appl. Entomol., 113:8-12.

Ferkovich, S. and Shapiro, J. 2004. Increased egg-laying in Orius insidiosus (Hemiptera: Anthocoridae) fed artificial diet supplemented with an embryonic cell line. Biol. Control, 31:11-15.

Grenier, S. and De Clercq, P. 2003. Comparison of artificially naturally reared natural enemies and their potential for use in biological control. In: van Lenteren JC (ed) Quality control and production of biological control agents: theory and testing procedures. CABI Publishing,Wallingford, UK, pp 115-131.

Grout, T. G. and Richards, R. I. 1992. The dietary effect of windbreak pollens on longevity and fecundity of a predacious mite Euseius addoensis (Acari: Phytoseiidae) found in citrus orchards in South Africa. Bull. Entomol. Res., 82: 317-320.

Kennett, C. E. and Hamai J. 1980. Oviposition and development in predaceous mites fed with artificial and natural diets (Acari: Phytoseiidae). Entomol. Exp. Appl. 28:116-122

Kutuk, H. and Yigit, A. 2011. Pre-establishment of Amblyseius swirskii (Athias-Henriot) (Acari: Phytoseiidae) using Pinus brutia (Ten.) (Pinales: Pinaceae) pollen for thrips (Thysanoptera: Thripidae) control in greenhouse peppers. Int. J. Acarol., 37:95-101.

Liu, W.; Xie, Z.; Xiao, G.; Zhou, Y.; Yang, D. and Li, L. 1979. Rearing of the Trichogramma dendrolimi in artificial diets. Acta. Phytophyl. Sin., 6:17-24.

Lu, X.; Han, S.; Li, L.; Grenier, S. and De Clercq,
P. 2012. The potential of trehalose to replace insect hemolymph in artificial media for Trichogramma dendrolimi Matsumura (Hymenoptera: Trichogrammatidae). Insect Sci.

McMurtry, J. A. and Croft, B. A. 1997. Life-styles of phytoseiid mites and their role in biological control. Annu. Rev. Entomol., 42: 291-321.

McMurtry, J. A. and Scriven, G. T. 1966. Effects of artificial foods on reproduction and development of four species of phytoseiid mites. Ann. Entomol. Soc. Am., 59:267-269.

Momen, F. and El-Saway, S. 1993. Biology and feeding behaviour of the predatory mite, Amblyseius swirskii (Acari: Phytoseiidae). Acarologia, 34:199-204.

Nettles, W. C. 1990. In vitro rearing of parasitoids: role of host factors in nutrition. Arch. Insect Biochem. Physiol., 13:167-175.

Ogawa, Y. and Osakabe, M. 2008. Development, long-term survival, and the maintenance of fertility in Neoseiulus californicus (Acari: Phytoseiidae) reared on an artificial diet. Exp. Appl. Acarol., 45:123-136.

Oliver, S. J. B.; Hoy, M. A. and Yaninek, J. S. 1996. Effect of some food source associated with cassava in Africa on the development, fecundity and longevity of Euseius fustis (Pritchard and Baker) (Acari: Phytoseiidae). Exp. Appl. Acarol., 20: 73-85.

Park, H. H.; Shipp, L. and Buitenhuis, R. 2010. Predation, development, and oviposition by the predatory mite Amblyseius swirkii (Acari: Phytoseiidae) on tomato russet mite (Acari: Eriophyidae). J. Econ. Entomol., 103:563-569.

Park, H. H.; Shipp, L.; Buitenhuis, R. and Ahn, J. J. 2011. Life history parameters of a commercially available Amblyseius swirskii (Acari: Phytoseiidae) fed on cattail (Typha latifolia) pollen and tomato russet mite (Aculops lycopersici). J. Asia- Pacific Entomol., 14:497501.

Riddick, E. W. 2009. Benefits and limitations of factitious prey and artificial diets on life parameters of predatory beetles, bugs, and lacewings: a mini-review. Biocontrol, 54:325339.

Shehata, K. K. and Weismann, L. 1972. Rearing the predaceous mite Phytoseiulus persimilis AthiasHenriot on artificial diet (Acarina: Phytoseiidae). Biol. Bratislava, 27:609-615.

Strand, M. and Vinson, S. 1985. In vitro culture of Trichogramma pretiosum on an artificial medium. Entomol. Exp. Appl., 39:203-209.

Thompson, S. 1999. Nutrition and culture of entomophagous insects. Annu. Rev. Entomol., 44:561-592.

Xu, X. N. and Enkegaard, A. 2010. Prey preference of the predatory mite, Amblyseius swirskii between first instar western flower thrips Frankliniella occidentalis and nymphs of the twospotted spider mite Tetranychus urticae. J. Insect. Sci., 10:149. 